IZA DP No. 8723

The Impact of Voluntary and Involuntary Retirement on Mental Health: Evidence from Older Irish Adults

Irene Mosca

Alan Barrett

December 2014 


\title{
The Impact of Voluntary and Involuntary Retirement on Mental Health: Evidence from Older Irish Adults
}

\author{
Irene Mosca \\ TILDA, Trinity College Dublin
}

Alan Barrett

Economic and Social Research Institute

and IZA

Discussion Paper No. 8723

December 2014

IZA
P.O. Box 7240
53072 Bonn
Germany

Phone: +49-228-3894-0

Fax: +49-228-3894-180

E-mail: iza@iza.org

\begin{abstract}
Any opinions expressed here are those of the author(s) and not those of IZA. Research published in this series may include views on policy, but the institute itself takes no institutional policy positions. The IZA research network is committed to the IZA Guiding Principles of Research Integrity.

The Institute for the Study of Labor (IZA) in Bonn is a local and virtual international research center and a place of communication between science, politics and business. IZA is an independent nonprofit organization supported by Deutsche Post Foundation. The center is associated with the University of Bonn and offers a stimulating research environment through its international network, workshops and conferences, data service, project support, research visits and doctoral program. IZA engages in (i) original and internationally competitive research in all fields of labor economics, (ii) development of policy concepts, and (iii) dissemination of research results and concepts to the interested public.
\end{abstract}

IZA Discussion Papers often represent preliminary work and are circulated to encourage discussion. Citation of such a paper should account for its provisional character. A revised version may be available directly from the author. 
IZA Discussion Paper No. 8723

December 2014

\title{
ABSTRACT \\ The Impact of Voluntary and Involuntary Retirement on Mental Health: Evidence from Older Irish Adults
}

The few studies that have attempted to identify the causal effects of retirement on mental health and well-being have provided conflicting evidence. Hence, whether retirement affects mental health positively or negatively is still unclear. Our primary objective is to investigate the impact of retirement on mental health as measured by the 20 -item Center for Epidemiological Studies Depression Scale (CES-D). We use data from the first two waves of The Irish Longitudinal Study on Ageing (TILDA). This is a nationally representative sample of individuals aged 50 and over and living in Ireland. To deal with possible endogeneity problems, we use first-differenced estimation models and control for a broad range of life events occurring between the two waves. These include transition to retirement but also demographic, social, economic and physical health events. As part of the TILDA survey, reasons for retirement are asked. We exploit this information and distinguish between individuals who retired voluntarily, involuntarily or because of own ill health. We find that involuntary, or forced, retirement has a negative and statistically significant effect on mental health. In contrast, we find no effects for voluntary retirement. We also find that retirement due to ill health is negatively associated with mental health.

JEL Classification: J26, J14

Keywords: retirement, mental health

Corresponding author:

\author{
Alan Barrett \\ Economic and Social Research Institute \\ Whitaker Square \\ Sir John Rogerson's Quay \\ Dublin 2 \\ Ireland \\ E-mail: alan.barrett@esri.ie
}




\section{The Impact of Voluntary and Involuntary Retirement on Mental Health: Evidence from Older Irish Adults}

\section{Introduction}

Population ageing is now understood to be one of the most significant economic challenges across the developed world, and beyond. As fertility and mortality rates fall, the age structure in many countries is changing in such as way that the number of people in the standard retirement-age bracket (65 and over) is rising relative to the number in the standard working-age bracket (16 to 64). This change in the old-age dependency ratio, all else equal, implies increasing challenges for sustaining elements of social spending such as pay-as-you-go pensions.

One proposal that is regularly made to counter the economic effects of population ageing is the postponement of retirement and the extension of working lives. By keeping people in the labour force for longer, two potential benefits can be achieved. First, longer working lives will translate into larger workforces, higher GDP and a larger tax base. Second, by working longer, people are better placed to deal with a situation in which pension benefits are paid later in life.

While the standard labour-leisure model of labour supply would suggest that later retirement would reduce life-time leisure and utility, a number of papers increasingly point to a benefit from later retirement. These papers argue that retirement can be associated with increased depression, reduced well-being and faster declines in cognitive abilities. Other papers however have cast doubt on the findings with respect to depression and suggest that retirement can be associated with improved mental health. Clearly, in the context of delayed retirement and extended working lives, it is important to better understand the impact of retirement on mental health.

In this paper, we explore the relationship between retirement and mental health using a rich new dataset from Ireland, the Irish Longitudinal Study on Ageing (TILDA). The TILDA data are particularly useful in this context for two reasons. First, TILDA is a 
panel dataset and we have two observations on the same people from 2009/11 and 2012/13. This means we observe people as they move from being employed to retired and we can see how their mental health changes. This means that we can overcome many of the endogeneity issues which afflict studies based on cross-sections. The second big advantage of the TILDA data for the present study is the fact that the data include good information on the reasons for retirement. People who are observed to have retired when being interviewed for the second wave of data collection are asked why they retired and the answers allow us to categorise retirees into voluntary and involuntary groups. This turns out to be a critically important distinction and suggests why other studies may have produced contradictory results.

The paper is structured as follows. In Section 2, we review the literature. In Section 3, we describe the data more fully and in Section 4 we set out our estimation framework. In Section 5 we discuss the results and we conclude in Section 6.

\section{Literature review}

Assessing the causal effect of retirement on mental health is complicated by two fundamental empirical challenges. The first challenge is unobserved heterogeneity, which arises because of the presence of unobserved factors that might affect both the decision to retire and mental health. Examples of such individual-specific factors are motivation, personality traits, productivity and time preferences. The second challenge is to make sure that the direction of causality flows from retirement to health rather than in the opposite direction. In addition to retirement affecting health outcomes, the literature has also identified causality in the other direction: people in worse health tend to retire (Bound et al., 1999; Coile, 2004; Currie and Madrian, 1999; Dwyer and Mitchell, 1999; Gustman and Steinmeier, 2002). Thus, observing poor (mental) health after retirement might not be the effect, but the cause of retirement.

The few studies that have attempted to identify the causal effects of retirement on mental health and well-being have used different strategies to overcome these empirical challenges. These include: fixed effects models to difference away the time-invariant 
within-person differences (Mandal and Roe, 2008; Dave et al., 2008; Latif, 2013; Charles, 2002); two-stage least square estimation to deal with the concern of reverse causation (Charles, 2002; Mandal and Roe, 2008; Latif, 2013; Neuman, 2008; Coe and Zamarro, 2011); sample stratification across individuals for whom retirement is likely to be exogenous to health (Dave et al., 2008); non-parametric estimators (Behncke, 2012) and regression discontinuity design (Johnston and Lee, 2009).

These studies have provided conflicting evidence. Dave et al. (2008) found that retirement leads to about a 6\% to 9\% decline in mental health. Mandal and Roe (2008) found that while involuntary job loss causes a significant deterioration in mental health, retirement improves mental health conditions. Charles (2002) and Johnston and Lee (2009) found that the direct effect of retirement on well-being is positive. Finally, Neuman (2008), Coe and Zamarro (2011) and Behncke (2012) found that retirement has no effect on depressive symptoms.

To our knowledge, only the study by Dave et al. (2008) has investigated the effect of involuntary retirement on mental health exploiting the information on retirement reasons provided directly by the respondents. Among the reasons leading to involuntary retirement, the authors included job displacement, employer policy towards older workers, care obligations and other personal reasons. Individuals reporting health as a retirement reason and individuals with mobility difficulties, illness conditions and psychological problems in the wave prior to retirement were excluded. The authors found some evidence that the adverse effects of retirement on mental health were larger in the event of involuntary retirement and smaller in the event of voluntary retirement.

\section{The data}

The data we use are from the first two waves of The Irish Longitudinal Study on Ageing. TILDA is a nationally representative sample of community dwelling individuals aged 50 and over (and their spouses and partners of any age) living in Ireland. It is modelled closely on the Health and Retirement Study (HRS), the English 
Longitudinal Study on Ageing (ELSA) and the Survey of Health, Retirement and Ageing in Europe (SHARE).

The first wave of data was collected between October 2009 and July 2011. A total of 8,504 participants were recruited from a clustered random sample of all households in Ireland. Respondents first completed a computer-assisted personal interview (CAPI) in their own homes. Respondents were then invited to travel to one of two health centres for a comprehensive health assessment. If unable or unwilling to attend a health centre, they were offered a modified and partial assessment in their own home. Respondents were also asked to complete a self-completion questionnaire (SCQ), which was designed to explore areas that were considered particularly sensitive, such as relationship quality, loneliness and stressful life events. A total of 6,910 respondents aged 50 and over completed and returned the SCQ. The overall response rate for the first wave of the study was $62 \%$. For more detail on the first wave of TILDA, see Whelan and Savva (2013).

The second wave of data was collected between April 2012 and January 2013 and a response rate of $86 \%$ was achieved (Dooley, 2014). Respondents completed a CAPI in their own homes and were asked to complete a SCQ. Unlike Wave 1 of the study, there was no health assessment at Wave 2. While every effort was made to achieve in-person interviews, 80 proxy interviews were carried out for respondents who were deemed unable to participate in an interview due a physical or cognitive impairment. Proxy interviews are excluded from our analyses, for the simple reason that we do not observe the relevant variables for these respondents. To account for the sampling structure at Wave 1 and non-response at Wave 2, we use appropriate survey estimation methods and weights that are available in the data. 


\section{The estimation framework}

\subsection{The model}

Given that we have two waves of data at our disposal, we apply first-differenced models. In so doing, we link changes in the explanatory variables over time with changes in the dependent variable over the same period. Our basic regression model is of the form:

$$
\Delta M H_{i}=\beta+\gamma \Delta S D_{i}+\delta \Delta E_{i}+\lambda \Delta P H_{i}+v \Delta R_{i}+\Delta u_{i}
$$

where $\Delta$ denotes a change in the variable between Wave 1 and Wave 2. $\Delta M H_{i}$ captures the change in the mental health status of individual i. On the right-hand side, we include vectors of changes in demographic and social variables $\left(\Delta S D_{i}\right)$, economic variables $\left(\Delta E_{i}\right)$ and physical health variables $\left(\Delta P H_{i}\right) . \Delta R_{i}$ is our independent variable of interest and indicates transition to retirement. $\Delta u_{i}$, is the change in the time-varying error.

A key benefit to the approach of the first-differenced model of Equation 1 is that timeinvariant unobservables that are likely to be correlated with both retirement decision and mental health, such as personality traits or productivity, are differenced away. In essence, the estimation using OLS of the first-differenced Equation 1 is identical to the estimation of a fixed-effects panel model.

An advantage of the TILDA data is that information is recorded on an unusually large variety of life events occurring between the two waves. Hence, in order to estimate the magnitude of the effect of retirement on mental health more precisely, we control for as many time-varying determinants of mental health as possible. As shown in Equation 1, these include demographic, social, economic and physical health events. Another advantage of the TILDA data is that reasons for retirement are sought at the time the individuals first report retirement. In particular, we are able to distinguish between individuals who retired voluntarily, involuntarily and due to own ill health. Using 
information on the reported reasons for retirement is an alternative method of identifying individuals whose retirement decisions are exogenous, or endogenous, to health.

Among the reasons leading to involuntary, or forced, retirement we include: redundancy or dismissal; no choice; and impossibility of finding another job. Among the reasons leading to voluntary retirement we include: eligibility for state/occupational/private pension; early retirement incentive offered by employer; opportunity to spend more time with partner/family; opportunity to enjoy life while still young and fit enough; opportunity to retire at the same time as husband/wife/partner; desire to give the young generation a chance; ill health of a relative/friend and 'other reasons', which respondents can specify.

Our sample includes 2,373 people, all of whom were employed at wave 1 of the survey. By wave 2, approximately 10 percent of them had retired (244, to be precise). Of this 244, 30 individuals retired involuntarily and 192 individuals retired voluntarily. The remaining 22 are individuals who retired because of own ill health. The variables employed in the model of Equation 1 are described in detail in Sections 4.2 and 4.3 below.

\subsection{Dependent variable: changes in depressive symptoms}

In TILDA, the 20-item Center for Epidemiological Studies Depression Scale (CES-D) is used to measure the degree to which respondents have experienced a wide variety of depressive symptoms in the week prior to the interview (Radloff, 1977). The test includes questions on negative feelings (like having the blues, experiencing life as a failure, feeling lonely or sad, having crying spells), on positive thoughts (as being hopeful about the future, feeling happy, enjoying life), on somatic activity (like losing appetite, suffering from a restless sleep, talking less), and on social contacts (experiencing other persons as unfriendly). Each of the 20 items is measured on a four point scale leading to a total score of 60 , with higher scores indicating higher depressive 
symptoms. A cutoff score of $\geq 16$ is used to determine clinically significant depressive symptoms (Radloff, 1977).

The CES-D scale has been commonly employed in the literature to measure distress and psychological well-being. Mandal and Roe (2008), Dave et al. (2008), Behncke (2012), Latif (2013) and Neuman (2008) also used this scale to study the effect of retirement on mental health. Similar to these studies, we treat the CES-D score as a continuous variable and estimate the first-differenced model of Equation 1 using OLS regression methods. Changes in depressive symptoms are obtained by subtracting the CES-D score at Wave 1 from the CES-D score at Wave 2. Positive changes indicate that depressive symptoms have increased between the two interviews. Negative changes indicate that depressive symptoms have decreased.

\subsection{Independent variables}

\subsubsection{Transition to retirement}

We first focus on our independent variable of interest: transition to retirement. At the first wave of TILDA, we observe 2,373 individuals who self-report to be employed (either self-employed or in paid employment). We then use dichotomous indicators to identify whether these individuals are: i) still in employment; or ii) fully retired at the time of Wave 2 data collection. We categorise respondents as fully retired if they report being retired at Wave 2 and not having done any paid work in the week prior to the interview. Individuals not otherwise in the labour force at either wave, including homemakers and those who are permanently sick or disabled, are excluded from the analysis. Also, as specified in Section 4.1 above, we stratify the sample across individuals who retired voluntarily, involuntarily or due to own ill health.

\subsubsection{Demographic and social changes}

We include two variables capturing whether respondents have experienced the death of a child, spouse or parent or the loss of close friends and/or relatives between the two survey waves. Death of family members and loss of close friends or relatives have 
regularly been shown as important sources of psychological stress (Choi and Bohman, 2007; Dykstra et al., 2005; Theeke, 2009),

TILDA respondents are also asked whether they participate in a group such as a sports or social group or club, a church connected group, a self-help or charitable body or a day care centre. We control for whether respondents no longer participate in a group if they report participation in a group at Wave 1 but not at Wave 2 .

\subsubsection{Economic changes}

As retirement is generally associated with a drop in income and changes in income may also affect mental health (Lindeboom et al., 2002; Dave et al., 2008; Mandal and Roe, 2008; Tiedt, 2013), we control for changes in weekly individual gross income. In TILDA, information on individual income is collected through a series of questions covering labour income and income from social welfare, pensions, investment incomes and other sources (O’Sullivan et al., 2014). The questions are taken directly from the recent versions of the European Union Statistics on Income and Living Conditions (EUSILC) questionnaire. ${ }^{1}$ As O’Sullivan et al. (2014) demonstrate, the distribution of income from TILDA and EU-SILC are closely aligned.

As a common problem with income data is the level of non-response, the technique of "unfolding brackets" is used in TILDA. Those who refuse or claim not to know the relevant amount in relation to an income question are asked a follow up question which gives the option of providing a banded answer rather than a point estimate. As shown by O’Sullivan et al. (2014), the use of unfolding brackets is a relatively successful interview strategy in TILDA. In our analysis, we use the mid-points of the unfolding brackets as the inputted data points for those who do not answers the original questions.

\footnotetext{
${ }^{1}$ Labour income consists of employee income from the respondent's main job in the past twelve months and the gross profit from self-employment for self-employed people as well as pre-tax farm income for those engaged in farming. Pension income is made up of both regular and lump sum income from occupational and private schemes. Social welfare payments made to the respondent, income from assets and irregular income are also included in our measure of gross income.
} 
Although the use of unfolding brackets reduces the problem of item non-response in relation to income sources, it does not eliminate it completely. An aggregated income figure cannot be computed for around $13.5 \%$ of our sample. Rather than discarding these observations, we keep them in our sample and identify five categories for changes in income: i) income has decreased; ii) income has increased/not changed; iii) income is missing at Wave 1; iv) income is missing at Wave 2; and v) income is missing at Wave 1 and Wave 2.

\subsubsection{Physical health changes}

TILDA includes a wide battery of questions on health status. Hence, we are in the fortunate position of being able to observe the extent to which the health status of TILDA respondents has changed or deteriorated between the two survey interviews. We employ changes in both subjective and objective health status. As Neuman (2008) points out, the combination of subjective and objective changes should reflect the true health changes experienced by respondents.

Focusing first on subjective changes in health status, we include two variables capturing whether respondents perceive that their physical health has deteriorated between the two survey waves. Self-rated physical health is measured using five response options “excellent, very good, good, fair, or poor”. We classify respondents by whether they have experienced a deterioration of one or two or more points in their physical health. To illustrate, a respondent who rates her physical health as very good in Wave 1 and good in Wave 2 would experience a one-point deterioration. A respondent who rates her physical health as very good in Wave 1 and fair in Wave 2 would experience a twopoint deterioration. We also control for whether respondents perceive that their vision has deteriorated since the last interview, since vision impairment has been found to be an important risk factor for depression and other mental health problems (Kennedy et al., 1990; Forsell, 2000).

Turning then to objective changes in health status, we control for the onset of disease and loss of functional capacity. Respondents are asked whether since the last interview they have been diagnosed with one or more cardiovascular condition or chronic illness. 
Examples of cardiovascular conditions are high blood pressure, high cholesterol and diabetes or more serious heart troubles including heart attack or stroke. Examples of chronic illnesses are asthma, arthritis, osteoporosis or cancer. Onset of cardiovascular disorders, other heart troubles and chronic illnesses are included as regressors. Respondents are also asked about any difficulties they have in carrying out a range of activities. These activities fall into two groups: activities of daily living (ADLs), which are the basic tasks of everyday life, such as eating, bathing, dressing, toileting, and moving about; and instrumental activities of daily living (IADLs), which are the activities performed in order to live independently in a community setting, such as managing money, shopping, using the telephone, housekeeping, preparing meals, and taking medications correctly. In our model, loss of functional capacity is measured by an increase in the number of ADLs and IADLs respondents have difficulties with.

In brief, we control for changes in both subjective and objective physical health and also isolate respondents who retired because of own ill health. By so doing, we are able to disentangle changes in health from the effect of health on retirement. For example, a newly diagnosed disease can be the cause of (or the justification for) retirement for some individuals but not for others. Our model enables us to capture this.

\section{Results}

\subsection{Descriptive statistics}

Table 1 illustrates the summary statistics for the 2,373 individuals in our sample, distinguished by labour market status at Wave 2. About $10 \%$ of the sample is fully retired, and the remaining $90 \%$ are continuously employed. The table illustrates the changes observed in CES-D score and the frequencies of events occurring between the two waves. Also, differences in baseline characteristics among the two groups are shown.

It can be seen that while individuals who are continuously employed have experienced, on average, a decrease in depressive symptoms, retirees have experienced, on average, 
an increase in depressive symptoms. To illustrate, the average change in the CES-D score experienced by individuals who are continuously employed is -0.378 . This compares to an increase of 0.783 for retirees. The difference between the two groups is statistically significant. Focusing on the other changes occurring between the two waves, one can see that retirees have experienced a steeper decline in physical health and in income. For example, weekly income has decreased for around $69 \%$ of retirees, compared to $41 \%$ of individuals who are continuously employed.

Looking finally at the baseline characteristics, Table 1 shows that important differences exist between the two groups at the time of Wave 1 data collection. The most striking difference is age: individuals who have retired are on average 5 years older than individuals who are still employed. This finding is in line with other international studies, including Behncke (2012) and Dave et al. (2008). Fully retired individuals are in poorer physical health but in better mental health at baseline.

\section{- Table 1 around here -}

As our models distinguish between individuals who retired voluntarily, involuntarily and due to ill health, Table 2 illustrates the average change in CES-D score experienced by these different groups, and compares them to the changes experienced by those who are continuously employed. The results of Table 2 show that the highest increase in CES-D score has been experienced by individuals who retired due to own ill health, followed by individuals who retired involuntarily and involuntarily. The mean increases in CES-D scores for these three groups are 3.041, 1.854 and 0.328, respectively.

\section{- Table 2 around here -}

\subsection{Regression results}

Table 3 reports the results of the first-differenced models which we have been put into operation by running OLS regressions in which changes in depressive symptoms are regressed on a wide range of changes in individuals' circumstances. Our primary aims 
are to understand whether retirement leads to poorer mental health and whether retiring because of different reasons affects mental health differently.

The results of two separate models are presented in the table. Model 1 simply distinguishes between individuals who are continuously employed and individuals who have transitioned to retirement between the two survey waves. In Model 2, retirees are divided into three groups according to whether retirement was involuntary, voluntary or due to own ill health. In both models, the reference category is made up of individuals who are continuously employed - that is, in employment at Wave 1 and still in employment at Wave 2.

Focusing first on our variable of interest, the results of Model 1 show that retirement has an adverse effect on mental health. Controlling for other events, the change in depression symptoms experienced by retirees is 1.05 points greater than the change experienced by individuals who are continuously employed. Turning now to the results of Model 2, one can see that voluntary retirement has no effect on mental health. In contrast, involuntary retirement affects mental health negatively. To illustrate, the change in depression symptoms experienced by retirees for whom retirement was involuntary is 2.21 points greater than the change experienced by individuals who are continuously employed. The positive and statistically significant coefficient of the variable 'retired due to own ill health' indicates a negative association between retirement and mental health for this group of individuals.

Turning to the other events occurring between the two waves, strong negative effects are found for a number of demographic and physical health events. Not surprisingly, bereavement is responsible for higher depressive symptoms. Similarly, loss in functional capacity, deterioration in self-rated physical health and vision are associated with higher depressive symptoms.

- Table 3 around here - 
We conclude our analysis by investigating whether unemployment, as opposed to involuntary retirement, also affects mental health negatively. We do so by including an additional category for individuals who are employed at Wave 1 and self-report being unemployed at Wave 2. We find that unemployment has an adverse but statistically insignificant effect on mental health. ${ }^{2}$ This finding might indicate that unemployment and forced/involuntary retirement are qualitatively different, with the latter having stronger negative mental health effects.

\section{Conclusions}

As policy-makers increasingly look to extend working lives in an effort to lessen the economic challenges of population ageing, it is important to understand more fully the impacts of retirement. If it could be shown that retirement had negative consequences such as a decline health status or deterioration in cognitive abilities, such findings could act to encourage people to remain in the labour force for longer and to forego additional leisure.

Our findings do not suggest that retirement improves mental health and instead show that retirement (broadly defined) leads to poorer mental health, at least in the immediate aftermath of retirement. However, a closer look at the data shows that this observed effect arises only for people whose retirement in involuntary or who retire due to illhealth. For people who retire voluntarily, there appears to be no mental health effects.

These findings are important because they may help to explain why studies in this area have uncovered differing results. Our results show that retirement has differing effects depending on whether a true choice that was present. When retirement is involuntary or due to ill-health, it seems that any psychic benefit that might arise from reduced stress or pressure is outweighed by factors such as a loss of social connectedness or other work-related positives. For people who retire voluntarily, the absence of a mental health gain suggests that this cannot be used in any effort to entice people to delay retirement. Instead, more standard economic incentives will be required such as actuarially-adjusted pension entitlements.

\footnotetext{
${ }^{2}$ Results are not presented in the paper but are available on request.
} 
Table 1: Descriptive statistics by labour market status at wave 2

\begin{tabular}{|c|c|c|c|c|}
\hline & \multicolumn{2}{|c|}{ Continuously employed } & \multicolumn{2}{|c|}{ Fully retired } \\
\hline & $\begin{array}{l}\text { Proportion } \\
\text { (mean) }\end{array}$ & $\begin{array}{l}\text { Standard } \\
\text { Deviation }\end{array}$ & $\begin{array}{l}\text { Proportion } \\
\text { (mean) }\end{array}$ & $\begin{array}{l}\text { Standard } \\
\text { Deviation }\end{array}$ \\
\hline \multicolumn{5}{|l|}{ Dependent variable } \\
\hline Change in CES-D score, mean & -0.378 & 6.087 & $0.783 * *$ & 5.566 \\
\hline \multicolumn{5}{|l|}{ Independent variables } \\
\hline \multicolumn{5}{|l|}{ Demographic/social changes: } \\
\hline Death of child/spouse/parent & 0.068 & 0.251 & 0.083 & 0.276 \\
\hline Loss of close relatives/friends & 0.435 & 0.496 & 0.456 & 0.499 \\
\hline Stopped participating in a group & 0.088 & 0.283 & 0.077 & 0.268 \\
\hline \multicolumn{5}{|l|}{ Health changes: } \\
\hline Loss in functional capacity (new ADL) & 0.008 & 0.090 & 0.026* & 0.158 \\
\hline Loss in functional capacity (new IADL) & 0.012 & 0.110 & 0.025 & 0.157 \\
\hline Onset of hypertension/high cholesterol/diabetes & 0.134 & 0.341 & $0.190 * *$ & 0.393 \\
\hline Onset of other heart problem & 0.030 & 0.172 & 0.047 & 0.211 \\
\hline Onset of chronic illness & 0.175 & 0.380 & $0.258^{*}$ & 0.438 \\
\hline 1-point deterioration in self-rated health & 0.199 & 0.399 & 0.206 & 0.405 \\
\hline 2+-point deterioration in self-rated health & 0.042 & 0.201 & 0.039 & 0.194 \\
\hline Deterioration in self-rated vision & 0.348 & 0.477 & 0.345 & 0.476 \\
\hline \multicolumn{5}{|l|}{ Economic changes: } \\
\hline Income has decreased & 0.407 & 0.491 & $0.693 * * *$ & 0.462 \\
\hline Income has increased/not changed & 0.461 & 0.499 & $0.142 * * *$ & 0.350 \\
\hline Missing income at Wave 1 & 0.067 & 0.249 & 0.081 & 0.274 \\
\hline Missing income at Wave 2 & 0.043 & 0.202 & 0.067 & 0.251 \\
\hline Missing income at Wave 1 and Wave 2 & 0.023 & 0.149 & 0.016 & 0.127 \\
\hline \multicolumn{5}{|l|}{ Baseline characteristics } \\
\hline Age, mean & 56.614 & 5.591 & $61.665 * * *$ & 5.409 \\
\hline Male & 0.591 & 0.492 & 0.568 & 0.496 \\
\hline Low education & 0.221 & 0.415 & 0.239 & 0.428 \\
\hline Medium education & 0.506 & 0.500 & 0.483 & 0.501 \\
\hline High education & 0.273 & 0.446 & 0.278 & 0.449 \\
\hline CES-D score, mean & 4.588 & 5.960 & $3.404 * * *$ & 4.402 \\
\hline Self-rated health, mean & 2.352 & 0.956 & 2.406 & 0.975 \\
\hline ADL, mean & 0.034 & 0.229 & $0.089 * *$ & 0.384 \\
\hline IADL, mean & 1.133 & 1.521 & $1.490 * * *$ & 1.870 \\
\hline Cardiovascular disorder, mean & 0.076 & 0.309 & 0.115 & 0.384 \\
\hline Chronic illness, mean & 1.133 & 1.078 & $1.464^{* * *}$ & 1.266 \\
\hline $\mathrm{N}$ & \multicolumn{2}{|c|}{2,129} & \multicolumn{2}{|c|}{244} \\
\hline
\end{tabular}

Differences between individuals who are continuously employed and fully retired significant at: *** $1 \%$

level; ** 5\% level; * 10\% level

Abbreviations: CES-D: Center for Epidemiological Studies Depression Scale; ADL: activity of daily

living; IADL: instrumental activity of daily living. 
Table 2: Average change in CES-D score by retirement group

\begin{tabular}{|l|l|l|l|l|l|l|l|l|}
\hline & \multicolumn{2}{|l|}{$\begin{array}{l}\text { Continuously } \\
\text { employed }\end{array}$} & \multicolumn{2}{l|}{$\begin{array}{l}\text { Retired due to ill } \\
\text { health }\end{array}$} & \multicolumn{2}{l|}{$\begin{array}{l}\text { Retired } \\
\text { involuntarily }\end{array}$} & \multicolumn{2}{l|}{$\begin{array}{l}\text { Retired } \\
\text { voluntarily }\end{array}$} \\
\hline & Mean & SD & Mean & SD & Mean & SD & Mean & SD \\
\hline Change in CES-D score & -0.378 & 6.087 & $3.041^{* *}$ & 7.751 & $1.854^{*}$ & 7.228 & $0.328^{*}$ & 4.834 \\
\hline $\mathrm{N}$ & 2,129 & 22 & 30 & 192 & \\
\hline
\end{tabular}

Differences with respect to individuals who are continuously employed significant at: *** 1\% level; ** $5 \%$ level; * $10 \%$ level

Abbreviations: CES-D: Center for Epidemiological Studies Depression Scale 
Table 3: Results of OLS regression. Outcome variable is change in CES-D score

between waves.

\begin{tabular}{|c|c|c|c|c|}
\hline & \multicolumn{2}{|l|}{ Model1 } & \multicolumn{2}{|l|}{ Model 2} \\
\hline & Coeff. & t stat. & Coeff. & t stat. \\
\hline \multicolumn{5}{|l|}{ Demographic/social changes: } \\
\hline Death of child/spouse/parent & $1.690^{* * *}$ & $(3.06)$ & $1.681^{* * *}$ & (3.07) \\
\hline Loss of close relatives/friends & 0.288 & $(1.03)$ & 0.275 & $(0.98)$ \\
\hline Stopped participating in a group & 0.208 & $(0.43)$ & 0.236 & $(0.48)$ \\
\hline \multicolumn{5}{|l|}{ Health changes: } \\
\hline Loss in functional capacity (new ADL) & 2.465 & $(0.86)$ & 2.352 & $(0.82)$ \\
\hline Loss in functional capacity (new IADL) & $3.629^{*}$ & $(1.94)$ & $3.507^{*}$ & $(1.90)$ \\
\hline Onset of hypertension/high chol./diabetes & -0.143 & $(-0.36)$ & -0.143 & $(-0.36)$ \\
\hline Onset of other heart problem & 0.843 & $(1.35)$ & 0.823 & $(1.33)$ \\
\hline Onset of chronic illness & 0.493 & $(1.16)$ & 0.474 & (1.11) \\
\hline 1-point deterioration in SR health & $0.785^{* *}$ & $(2.24)$ & $0.777^{* *}$ & (2.23) \\
\hline 2+-point deterioration in SR health & $1.603^{* *}$ & $(2.25)$ & $1.583^{* *}$ & $(2.23)$ \\
\hline Deterioration in self-rated vision & $0.605^{* *}$ & $(2.16)$ & $0.622^{* *}$ & $(2.22)$ \\
\hline \multicolumn{5}{|l|}{ Economic changes: } \\
\hline Income has increased/stayed the same & Ref. & Ref. & Ref. & Ref. \\
\hline Income has decreased & -0.149 & $(-0.50)$ & -0.151 & $(-0.51)$ \\
\hline Missing income at Wave 1 & -0.157 & $(-0.25)$ & -0.149 & $(-0.23)$ \\
\hline Missing income at Wave 2 & -0.0741 & $(-0.14)$ & -0.0303 & $(-0.06)$ \\
\hline Missing income at Wave 1 and Wave 2 & 1.159 & $(1.59)$ & 1.200 & $(1.64)$ \\
\hline \multicolumn{5}{|l|}{ Transition to retirement: } \\
\hline Continuously employed & Ref. & Ref. & Ref. & Ref. \\
\hline Fully retired & $1.052^{* *}$ & $(2.54)$ & -- & -- \\
\hline Retired due to own ill health & -- & -- & $2.584^{*}$ & (1.85) \\
\hline Retired involuntarily & -- & -- & $2.212^{*}$ & (1.71) \\
\hline Retired voluntarily $^{\mathrm{a}}$ & -- & -- & 0.674 & $(1.56)$ \\
\hline Constant & $-1.181^{* * *}$ & $(-4.52)$ & $-1.177^{* * *}$ & $(-4.51)$ \\
\hline $\mathrm{N}$ & \multicolumn{2}{|c|}{2,273} & \multicolumn{2}{|c|}{2,273} \\
\hline
\end{tabular}

${ }^{*} \mathrm{p}<0.10,{ }^{* *} \mathrm{p}<0.05, * * * \mathrm{p}<0.01$

Note: For events like widowhood or onset of disease, the change between the two waves is a dichotomous variable equal to 1 if the event happened; 0 otherwise. 


\section{References}

Behncke, S. (2012). Does Retirement Trigger Ill Health? Health Economics, 21: 282300.

Bound J, Schoenbaum M, Stinebrickner TR, Waidmann T (1999). The dynamic effects of health on the labor force transitions of older workers. Labour Economics 6:179-202.

Charles, K.K. (2004). Is retirement depressing? Labor force inactivity and psychological well-being in later life. Research in Labor Economics, 23: 269-299.

Choi, N.G. and T.M. Bohman (2007). Predicting the Changes in Depressive Symptomatology in Later Life. How Much Do Changes in Health Status, Marital and Caregiving Status,Work and Volunteering, and Health-Related Behaviors Contribute?, Journal of Aging and Health 19(1): 152-177.

Coe, N.B. and Zamarro, G. (2011) Retirement effects on health in Europe. Journal of Health Economics, 30: 77-86.

Coile CC (2004) Health shocks and couples’ labor supply decisions. NBER Working Paper 10810.

Currie J, Madrian BC (1999) Health, health insurance and the labor market. In: Ashenfelter O, Card D (eds) Handbook of labor economics, vol 3, part 3. Elsevier B.V., Oxford, pp 3309-3415.

Dave, D., Rashad, I. and Spasojevici, J. (2008). The Effects of Retirement on Physical and Mental Health Outcomes. Southern Economic Journal, 75(2), 497-523.

Dooley, C. (2014), “Methodology”, chapter 7 in Anne Nolan, Claire O’Regan, Cara Dooley et al. (eds.). The Over 50s in a Changing Ireland: Economic circumstances, Health and Well-Being, Trinity College Dublin. 
Dykstra, P.D., T.G. van Tilburg and J.de Jong Gierveld (2005). Changes in Older Adult Loneliness: Results From a Seven-Year Longitudinal Study. Research on Aging 27:725747

Dwyer DS, Mitchell OS (1999) Health problems as determinants of retirement: are selfrated measures endogenous? Journal of Health Economics, 18:173-193.

Forsell, Y. (2000). Predictors for Depression, Anxiety and psychotic symptoms in a very elderly population: data from a 3-year follow-up study. Social Psychiatry and Psychiatric Epidemiology, 35:259-263.

Gustman AL, Steinmeier TL (2002) The Social Security Early Entitlement Age in a Structural Model of Retirement and Wealth. NBER Working Paper 9183.

Johnston, D.W and Lee W-S. (2009) Retiring to the good life? The short-term effects of retirement on health. Economics Letters, 103: 8-11

Kennedy GJ, Kelman HR, Thomas C. (1991). Persistence and remission of depressive symptoms in late life. American Journal of Psychiatry, 148(2):174-8.

Latif, E. (2012). The Impact of Retirement on Health in Canada. Canadian Public Policy, 38(1): 15-29.

Latif, E. (2013). The Impact of Retirement on Mental Health in Canada. The Journal of Mental Health Policy and Economics, 16(1): 35-46.

Lindeboom, M., F. Portrait and G.J. van den Berg (2002), An Econometric Analysis of the Mental-Health Effects of Major Events in the Life of Older Individuals, Health Economics and Econometrics, 11: 505-520

Mandal, B. And Roe, B. (2008). Job Loss, Retirement and the Mental Health of Older Americans. The Journal of Mental Health Policy and Economics, 11, 167-176. 
Neuman K. (2008). Quit your job and get healthier? The effect of retirement on health. Journal of Labor Research 29:177-201.

O'Sullivan, V., Nolan, B. and Barrett, A., Dooley, C. (2014) Income and Wealth in the Irish Longitudinal Study on Ageing. Economic and Social Review [In press].

Radloff, L.S. (1977). “The CES-D scale: A Self-report Depression Scale for Research in the General Population”, Applied Psychological Measurement 1:385-401.

Theeke, L.A. (2009). Predictors of Loneliness in U.S. Adults Over Age Sixty-Five, Archives of Psychiatric Nursing, 23(5): 387-396.

Tiedt, AD. (2013). Cross-National Comparisons of Gender Differences in Late-Life Depressive Symptoms in Japan and the United States, Journals of Gerontology, Series B: Psychological Sciences and Social Sciences, 68(3): 443-454.

Whelan, B.J. and Savva, G.M. (2013). Design and Methodology of the TILDA Study. Journal of the American Geriatrics Society, 61(s2): S265-68. 